\title{
Urbano Orad y Gajías (1849-1935): Médico, héroe de guerra y masón
}

\author{
Urbano Orad y Gajías (1849-1935): \\ Medical, War Hero and Freemason
}

\author{
Manuel de Paz Sánchez \\ Universidad de La Laguna, Islas Canarias, España \\ mdepaz@ull.edu.es
}

Recepción: 18 de septiembre de 2017/Aceptación: 31 de octubre de 2017

doi: https://doi.org/10.15517/rehmlac.v9i1.27890

Palabras clave

Historia de la Sanidad Militar; Urbano Orad Gajías; Independencia de Cuba; Melilla; Africanismo español; Regeneracionismo.

Keywords

History of Military Health; Urbano Orad Gajías; Independence of Cuba; Melilla; Spanish Africanism; Political and Institutional Regeneration.

Resumen

Este apunte biográfico pretende reflexionar sobre algunos de los aspectos principales de la vida del médico militar y coronel del cuerpo de Inválidos, don Urbano Orad y Gajías. Se trata de un personaje relevante en la historia del cuerpo de Sanidad Militar, que participó activamente en los conflictos que jalonaron la historia de España en la transición del siglo XIX al XX (Cuba y el Norte de África), y que mereció la máxima recompensa militar. También se ha estudiado su vinculación con la masonería, su ideario reformista y su activa participación en importantes eventos socio-culturales como el Segundo Congreso Africanista (Zaragoza, 1908). Se ha comparado brevemente su semblanza con la de otros destacados personajes del periodo, que supieron conjugar su reformismo y su crítica social e institucional con un elevado sentido del patriotismo español en un contexto regeneracionista.

\section{Abstract}

This biographical note aims to reflect on some aspects of the military doctor and colonel, Urbano Orad y Gajías's life. He is a leading figure in the history of the Military Health of Spain. He fought in the wars of Cuba and North Africa, at the turn of the $20^{\text {th }}$ century, and earned the highest military reward granted in Spain. We have also studied his relationship with Freemasonry, his reformist ideas and his active participation in important socio-cultural events such as the Second Congress of Africanist (Zaragoza, 1908). In addition, we have compared his biography with other prominent figures from the same period. They combined their reformism and critical spirit with a high sense of Spanish patriotism, in an environment marked by Spain's 1898 regeneration movement.

\section{Introducción}

La importancia de los vínculos entre España y Cuba, el florón de la corona, y la trascendencia de las relaciones de la Península con Marruecos y otros enclaves del Norte de 
África, en la transición del siglo XIX al XX, han sido objeto de diversos estudios y monografías de interés ${ }^{1}$. En fechas recientes se ha subrayado, además, la necesidad de esbozar un nuevo paradigma interpretativo para el análisis de esta importantísima y compleja relación Norte-Sur, en referencia al caso concreto del antiguo Imperio cherifiano y sus vínculos con España. Ello implicaría prestar una especial atención a la influencia del proyecto regeneracionista en la elaboración y puesta en práctica del programa africanista de la Restauración ${ }^{2}$.

Existen, además, diversos trabajos sobre la presencia de organizaciones masónicas en las plazas de soberanía y en Marruecos ${ }^{3}$, pero se requieren nuevos estudios, como los que se están llevando a cabo en la actualidad ${ }^{4}$, para evaluar la importancia de la Orden del Gran Arquitecto en el Magreb español y, en concreto, para conocer las actuaciones de algunos de sus integrantes más representativos. La presencia de miembros de las diversas armas y cuerpos militares en la mayor parte de estos talleres masónicos posee, además, un notable interés ideológico-cultural, dada la singularidad de la masonería en el contexto hispánico.

\footnotetext{
${ }^{1}$ José Manuel Allendesalazar, La diplomacia española y Marruecos, 1907-1909 (Madrid: Ministerio de Asuntos Exteriores, 1990). Eloy Martín Corrales, Marruecos y el colonialismo español (1859-1912): de la guerra de África a la "penetración pacífica" (Barcelona: Bellaterra, 2002). Vicente Moga Romero, La cuestión marroqui en la escritura africanista: una aproximación a la contribución bibliográfica y editorial española al conocimiento del Norte de Marruecos (1859-2006) (Barcelona: Ed. Bellaterra, 2008). Víctor Morales Lezcano, España y el Norte de África: el Protectorado en Marruecos (1912-1956) (Madrid: UNED, 1986). Víctor Morales Lezcano, El colonialismo hispano-francés en Marruecos (1898-1927) (Granada: Universidad de Granada, 2002). Francisco M. Pastor Garrigues, A las puertas del Protectorado: las negociaciones secretas hispano-francesas en torno a Marruecos (1901-1904) (Sevilla: Universidad de Sevilla, 2013). Javier Ramiro de la Mata, Origen y dinámica del colonialismo español en Marruecos (Ceuta: Archivo Central, 2002). Jesús F. Salafranca Ortega, El sistema colonial español en África (Málaga: Algazara, 2001). Alfonso de la Serna, Al sur de Tarifa: España-Marruecos: un malentendido histórico (Madrid: Marcial Pons, 2002). Akmir Youssef, De Algeciras a Tetuán, 1875-1906: orígenes del proyecto colonialista español en Marruecos (Rabat: Instituto de Estudios Hispano-Lusos, 2009); entre otros.

${ }^{2}$ Francisco Javier Martínez Antonio e Irene González González eds., Regenerar España y Marruecos: ciencia y educación en las relaciones hispano-marroquies a finales del siglo XIX (Madrid: Consejo Superior de Investigaciones Científicas, 2011), 11.

${ }^{3}$ Vicente Moga Romero, "Aproximación a la masonería de Ceuta en el siglo XIX", en La masonería en la España del siglo XIX, coord. José Antonio Ferrer Benimeli (Zaragoza: CEHME y Junta de Castilla y León, 1987), Tomo I, 297-309. Vicente Moga Romero, Al "Oriente" de África: Masonería, Guerra Civil y represión en Melilla (1894-1936) (Melilla: UNED, 2005), 2 vols. Francisco Sánchez Montoya, "Los libros falsos de Tánger y apuntes sobre la represión de la masonería en Ceuta", en La masonería en Madrid y en España del siglo XVIII al XXI, coord. Ferrer Benimeli (Zaragoza: CEHME, 2004), Tomo II, 1157-1163. Manuel de Paz Sánchez, La masonería y la pérdida de las colonias. Estudios (Santa Cruz de Tenerife: Ediciones Idea, 2006). De Paz Sánchez, "España, Cuba y Marruecos: masonería, identidades y construcción nacional", Anuario de Estudios Atlánticos 55 (2009): 273-310.

${ }^{4}$ Como, por ejemplo, la tesis doctoral en curso de Valeria Aguiar Bobet, que realiza en la Universidad Jaume I de Castellón sobre la Gran Logia de Marruecos.
} 
En estas páginas se recoge, pues, un esbozo biográfico del médico militar Urbano Orad y Gajías (Alfajarín [Zaragoza], 31 de octubre de 1849-Madrid, 18 de febrero de $1935)^{5}$, caballero de San Fernando y figura destacada en dos escenarios relevantes: Cuba y el Norte de África. Por sus hechos y por su valor mereció en Cuba la máxima recompensa militar, mientras que en el Norte de África, particularmente en Melilla ${ }^{6}$, desarrolló una destacada labor que se tradujo en una serie de propuestas reformadoras. Buena prueba de ello fue, por ejemplo, su activa participación en el Segundo Congreso Africanista, celebrado (1908) en Zaragoza, donde planteó diversas reflexiones que tendrían notable repercusión en la prensa y en círculos profesionales e institucionales.

\section{Entre Cuba y Melilla}

Orad pasó a las Antillas, prácticamente, nada más integrarse en el cuerpo de Sanidad Militar ${ }^{7}$, tras haberse licenciado (1876) en Medicina por la Universidad de Zaragoza $^{8}$, puesto que, desde septiembre de 1877, figuró en distintas convocatorias para cubrir vacantes en $\mathrm{Cuba}^{9}$. Llegó a la isla cuando ya se habían acordado las paces, el 28 de febrero de 1878, aunque estuvo destinado en campaña hasta el 9 de junio, "que se dio por terminada la guerra", tal como reza su hoja de servicios ${ }^{10}$. En el Hospital de La Habana hizo frente durante los meses de junio a septiembre de 1879 , junto a sus compañeros, a un brote de fiebre amarilla, por cuya eficiente labor fueron felicitados y se les hizo constar el servicio en sus respectivos expedientes militares. En febrero de 1880 formó parte de la plantilla del centro hospitalario de Jiguaní, donde prestó servicios relacionados con los últimos movimientos de tropas de la llamada Guerra Chiquita (1879-1880), epílogo de la anterior. Justo un año después, en febrero de 1881, ejerció en el Hospital de Santa Clara, pero contrajo las fiebres y, en anticipo de licencia, embarcó rumbo a la Península el 25 de mayo $^{11}$. Se le ascendió a médico mayor "graduado" a mediados de octubre de $1881^{12}$,

\footnotetext{
${ }^{5}$ El error de datar su nacimiento en 1843 y no en 1849, como corresponde, proviene de su propia hoja de servicios (Archivo General Militar, Segovia, O-404), que contiene este y otros yerros. Los anuarios militares, entre 1891 y 1899 , llevan la fecha correcta, pero, a partir de 1900 y hasta 1935 , se sigue estrictamente la hoja de servicios y se indica todo el tiempo la fecha errónea. Respecto al óbito, como luego veremos, se produjo el 18 de febrero, no el 16, que es otro error. Su segundo apellido, además, ofrece distintas variantes, las principales son Gagías y Gajías, tanto con tilde como sin ella.

${ }^{6}$ Moga Romero, Al "Oriente” de África, Tomo I, 120-121.

${ }^{7}$ Se recogió su ingreso como médico segundo en La Gaceta de Sanidad Militar (en adelante GSM), 62, 25 de julio de 1877, 393, según real decreto del día 15.

${ }^{8}$ Alejandro Belaústegui Fernández, José Salvany y otros médicos militares ejemplares. Inicio de una lucha contra el olvido (Madrid: Ministerio de Defensa, 2006), 86.

${ }^{9}$ GSM, 66, 25 de septiembre de 1877, 497; El Globo, 23 de diciembre de 1877, 3. Mientras no se especifique el lugar de publicación nos referiremos a periódicos de Madrid.

${ }^{10}$ Hoja de servicios, fol. 10.

${ }^{11}$ Se aprobó el permiso oficialmente el 8 de junio y, el 10 de noviembre, se le concedieron dos meses de prórroga, tal como se recoge en su hoja de servicios. También GSM, 156, 25 de junio de 1881, 355.
} 
precisamente "en recompensa a los servicios de campaña prestados hasta la pacificación de la Comandancia General de Holguín, el 16 de octubre del año anterior" [1880] $]^{13}$, pero, en realidad, el empleo no se hizo efectivo hasta 1895. En Cuba, donde ejerció su profesión en diferentes hospitales militares y civiles entre finales de 1881, en que regresó a la isla, y 1885 en que se casó y volvió a la Península ${ }^{14}$, tuvo también algún que otro conflicto con los políticos y periodistas locales ${ }^{15}$, al menos entre 1883 y $1884^{16}$.

Vivió en Zaragoza hasta 1889. En agosto de 1888 contribuyó con dos pesetas a la suscripción abierta para construir un monumento en memoria de los miembros del cuerpo, muertos en campaña ${ }^{17}$. Entre 1889 y 1894 residió en Melilla, salvo 1892 en que estuvo destinado en Ceuta. El 5 de septiembre de 1890 figuraba como "médico primero personal, segundo efectivo" y estaba, en comisión, al frente del Hospital militar del Peñón de Vélez de la Gomera. Se le concedió por entonces un mes de permiso, para Orán, por asuntos propios $^{18}$.

El matrimonio Orad-de la Torre no tardaría en protagonizar en Melilla un hecho que tuvo cierto eco en la prensa nacional. El corresponsal de Las Dominicales del Libre Pensamiento no dudó en titularlo "Tolerancia en acción". El 16 de marzo de 1891, tras dos semanas de "precursoras ceremonias", habían contraído matrimonio la señorita Mercedes Benhamu, "hija del hebreo tan conocido y estimado en esta plaza, Sr. Abraham", y el joven David Melhabea, hijo igualmente de un joyero judío de Orán ${ }^{19}$.

La novedad era que los padrinos de la boda habían sido el médico Orad y su esposa, Blanca Rosa de la Torre y Morales $^{20}$, circunstancia que había llamado la atención por ser el primer caso del que se tenía noticia y que constituía un augurio de que "iban desapareciendo los rencores engendrados por las diferencias de religión". Esta "comunión humana entre hebreos y españoles" había despertado la curiosidad y las simpatías de la población. Se había traído expresamente una orquesta de Orán y, asimismo, asistieron a la fiesta algunas personalidades como el general José Mirelis González, acompañado de su hija. Sobresalió, en fin, la conducta de los padrinos, ya que "despreciando rancias preocupaciones, han contribuido a la realización de este hermoso acto de confraternidad".

\footnotetext{
${ }^{12}$ GSM, 164, 25 de octubre de 1881, 574.

${ }^{13}$ Hoja de servicios, fol. 12. Es decir, en relación con la citada campaña menor de la Guerra Chiquita.

${ }^{14}$ Hoja de servicios, fol. 13.

${ }^{15}$ Entre los meses de febrero y marzo de 1884, por ejemplo, estuvo sometido a un procedimiento en Santiago de Cuba, pero la sumaria "por lesiones a un paisano" fue sobreseída el 29 de mayo, por providencia del Consejo Supremo de Guerra y Marina, "sin que la formación de dicho procedimiento le sirva de nota ni perjuicio en su carrera" (Hoja de servicios, fols. 12-13).

16 Juan Vicente Hernández, La prensa en el Archivo General Militar de Segovia: catálogo (1810-1935) (Madrid: Fundación Mapfre Tavera, 2004), 105-106.

${ }^{17}$ Revista de Sanidad Militar (en adelante RSM), 27, 1 de agosto de 1888, 232.

${ }^{18}$ Diario Oficial del Ministerio de la Guerra (en adelante DOMG), 200, 7 de septiembre de 1890, Tomo III, 1769.

${ }^{19}$ Las Dominicales del Libre Pensamiento, 28 de marzo de 1891, 3.

${ }^{20}$ Natural de La Habana (El País, 13 de julio de 1895, 2).
} 
Otros periódicos se hicieron eco de estos esponsales. La Lucha de Gerona, un diario liberal que dirigía Joaquín Ruiz Blanch, le dedicó todo un artículo de fondo, en el que se preguntaba, entre otras cuestiones, si acaso eran "menos bárbaros que los marroquíes" los contendientes de varias procedencias europeas que habían participado en la última guerra carlista $^{21}$.

A los pocos meses fue ascendido ${ }^{22}$, y se le destinó como "médico mayor graduado, primero efectivo", al Hospital militar de Ceuta ${ }^{23}$. No debió ser de su agrado, pues, a finales de 1892 se le concedió el pase a la situación de reemplazo ${ }^{24}$, con residencia en Melilla, para donde embarcó con los suyos el 10 de enero de $1893^{25}$.

Las tensiones surgidas con las cabilas fronterizas, sobre todo por la proximidad de las obras del fuerte de Sidi Uariach a territorio sagrado para los musulmanes, desembocaron en los sucesos de Melilla, entre octubre de 1893 y abril de 1894, conocidos como la guerra de Margallo, en alusión al comandante de la plaza, Juan García-Margallo. A Melilla llegaron entonces nuevos oficiales y jefes que se habían integrado en las logias en diferentes destinos, tanto de la Península como de Ultramar, de ahí que, como se ha señalado, la guerra no fue un obstáculo sino, al contrario, un impulso favorable a la implantación masónica en el Norte de África ${ }^{26}$.

Orad y Gajías era un soldado de bata blanca y, por ello, se reincorporó de forma inmediata al ejército. Es más, como confesaría años más tarde, hubo una época de su vida en la que se sintió más soldado que médico. "Yo era médico, pero nací para soldado. Indudablemente", le dirá al periodista que, a principios de 1930, le preguntó en qué hecho, cómo y cuándo había ganado la "Laureada"27, asunto del que enseguida se hablará.

Así, pues, a principios de octubre de 1893, es decir, durante los primeros enfrentamientos de la guerra de Margallo, el médico Orad no tardó en merecer calificativos heroicos en la prensa. En efecto, desde el propio combate del 2 de octubre, "ardiendo en patriótico entusiasmo", había pedido permiso a los jefes del fuerte de Los Camellos, donde se encontraba destinado, para entrar en la pelea y, tomando un fusil, se fue "valientemente a las guerrillas y allí, confundiéndose con los soldados, siendo uno más entre los heroicos defensores de la patria, se estuvo batiendo denodadamente contra los rifeños, hasta que le avisaron para curar a los heridos" 28 . La noticia tuvo repercusión en otros medios ${ }^{29}$, pero $E l$

\footnotetext{
${ }^{21}$ Joaquín Barnó, “Africanos y europeos”, La Lucha, 24 de abril de 1891, 1.

${ }^{22}$ El Correo Militar (en adelante CM), 17 de agosto de 1891, 3. El 27 de julio, concretamente.

${ }^{23}$ DOMG, 206, 23 de septiembre de 1891, Tomo III, 785.

${ }^{24} \mathrm{CM}, 23$ de diciembre de 1892, 2.

${ }^{25}$ El África, Ceuta, 14 de enero de 1893, 3.

${ }^{26}$ Moga Romero, Al "Oriente" de África, Tomo I, 96-102.

${ }^{27}$ C. Jaquotot, "Los caballeros de San Fernando. ¿En qué hecho, cómo y cuándo ganó usted la laureada? Don Urbano Orad, coronel de Inválidos", La Nación, 12 de febrero de 1930, 14.

28 "Elogios.- El general Margallo. Un médico que se bate”, El Liberal, 9 de octubre de 1893, 1. También hoja de servicios, fol. 14, en la que se destaca que se encontraba aún en situación de reemplazo.

29 “Agresión de los Riffeños”, CM, 9 de octubre de 1893, 2.
} 
Liberal, su principal valedor en esta época, se esmeró particularmente y publicó su retrato el 30 de noviembre, con el siguiente pie: "D. Urbano Orad. Médico primero de Sanidad Militar. Está encargado de la clínica de heridos del Hospital Militar de Melilla. Se batió en las guerrillas y salvó la vida al artillero Trinidad Ponce"30.

Estos militares, en cierta manera "hijos y nietos" de Prim y de La Gloriosa, se habían iniciado en la masonería por diversas razones, desde la existencia de tradiciones familiares, pasando por la desenvoltura típica de los años juveniles $\mathrm{y}$, en un porcentaje nada despreciable, para integrarse en redes de sociabilidad republicana y librepensadora. Todo ello, además, inscrito en la moda orientalista que, entre finales del XIX y primeras décadas del XX, había llevado a muchos de estos hombres de alta clase media a afiliarse a organizaciones teosóficas y espiritualistas.

El movimiento masónico hispano-marroquí, por si fuera poco, había contado en sus filas con destacadas figuras militares, como fueron Julio Cervera Baviera, Venancio Álvarez Cabrera y otros jefes y oficiales que, en 1890, erigieron el Grande Oriente de Marruecos $^{31}$. Pero, al año siguiente, la potencia masónica creada por Cervera junto a diversas personalidades del majzén, al objeto de establecer la primera organización que cohesionara masónicamente el territorio magrebí, se integró en el Grande Oriente Español, organismo fundado (1889) y dirigido, desde Madrid, por el profesor Miguel Morayta Sagrario.

A mediados de marzo de 1894, el Grande Oriente Español delegó en Julio Cervera para que procediera a la instalación, en Melilla, de la logia África no. 202, compuesta mayoritariamente por militares. La creación de esta logia vino a coincidir, casi de forma milimétrica, con el final de la guerra de Margallo. Su primer venerable sería, precisamente, Urbano Orad y Gajías, que poseía el nombre simbólico de Palafox y el grado 18 del rito escocés antiguo y aceptado ${ }^{32}$. Orad pudo iniciarse en Cuba, durante su primera estancia en la isla, o bien a su regreso a la península. Lo cierto es que, al poco tiempo de hacerse cargo del mallete, fue elevado al grado 30. También fue exaltado a caballero kadosch el fundador

\footnotetext{
${ }^{30}$ El Liberal, 30 de noviembre de 1893, 1. Este mismo periódico había reunido 100 pesetas que fueron distribuidas entre los heridos del hospital militar de la plaza de soberanía, según sus necesidades, para lo que el encargado del reparto, Ortiz de Pinedo, contó con el asesoramiento del propio Orad (El Liberal, 16 de noviembre de 1893, 1). El Imparcial (22 de octubre de 1893, 2) se había hecho eco, por su parte, de su destino al citado centro hospitalario de Melilla.

${ }^{31}$ Vicent Sampedro Ramo, Julio Cervera Baviera, republicano y masón (Castellón de la Plana: Universitat Jaume I, 2015), 323-330. Moga Romero, Al "Oriente” de África, Tomo I, 72-88. Jorge Pina, "Julio Cervera Baviera. Apuntes biográficos", en Conmemoración de la expedición científica de Cervera-Quiroga-Rizzo al Sáhara Occidental en 1886, ed. José A. Rodríguez Esteban (Madrid: CSIC, 2008), 175-206.

${ }^{32}$ Vicente Moga Romero y Adoración Perpén Rueda, "Orígenes ideológicos de los talleres masónicos contemporáneos en Melilla: militares y masonería (1893-1927)", en Masonería, revolución y reacción, coord. José Antonio Ferrer Benimeli (Alicante: CEHME y Diputación Provincial de Alicante- Instituto Alicantino de Cultura Juan Gil-Albert, 1990), Tomo II, 717-741. Moga Romero, Al “Oriente” de África, Tomo I, 107-109, 116, 122. Sampedro Ramo, Julio Cervera Baviera, 336.
} 
y orador Manuel Rosillo, que pertenecía al cuerpo de administración militar y que, al igual que Orad, fue destinado a Cuba de forma inmediata ${ }^{33}$. Según Vicente Moga Romero ${ }^{34}$, Orad causó baja en la logia el $1^{\circ}$ de junio de 1894, justamente el mismo día en que, según su citada hoja de servicios, partió rumbo al Caribe.

\section{La acción de Cacao y el "bravo médico Orad"}

El parte telegráfico oficial remitido a Madrid, el 9 de julio de 1895, por el gobernador y capitán general de Cuba, Arsenio Martínez Campos, fue el siguiente:

General del segundo distrito participa que Rabí con 800 hombres atacó columna comandante Sánchez, de 360 hombres, a la entrada de Cacao, el 27 de Junio. La columna intentó cuatro veces tomar una posición favorable, sin resultado, siguiendo fuego hasta ocho noche que, pasado arroyo, se reconcentró la fuerza, siguiendo hasta Guisa, a donde llegó en la mañana del 28. El médico Orad y 40 hombres, a pesar oído toque retirada, siguieron fuego, retirando heridos y dos cajas de municiones, rechazando enemigo, formando convoy, transportando heridos separados de la columna, llegando a Jiguaní cuatro mañana. Tuvimos varios muertos y heridos, entre los segundos, el bravo médico Orad. No precisan bajas del enemigo, supuestas numerosas ${ }^{35}$.

Las noticias del combate, todavía confusas, habían circulado por Madrid desde la madrugada del 6 de julio, y empezaron a ser difundidas por los grandes rotativos a partir del día siguiente ${ }^{36}$. El día 11, todo el mundo estaba al tanto de la posible caída del "médico valiente" en la acción de Cacao, cerca de Jiguaní, en la provincia más oriental de Cuba ${ }^{37}$. Su presunto fallecimiento venía a sumarse al de otro médico militar, muerto heroicamente el 13 de mayo de 1895 en la acción de Jovito, al que le había sido concedida la Laureada ${ }^{38}$. El Imparcial unió ambos nombres en holocausto patriótico: “Así Ruiz, así Orad, mártires

\footnotetext{
${ }^{33}$ El CM del 18 de abril de 1894, 3, aludió a la orden de traslado de Orad a la Perla de las Antillas, que databa del día 14 de dicho mes y año. Hoja de servicios, fol. 14.

${ }^{34}$ Al "Oriente" de África, Tomo II, 904-905.

${ }^{35}$ RSM, 194, 15 de julio de 1895, 241; Fernando Soldevilla, Año político. 1895 (Madrid: Imp. de Enrique Fernández de Rojas, 1896), 333-334. Orad se había incorporado, en comisión, al hospital militar de Bayamo el 10 de mayo y, una semana después, entró en campaña (Hoja de servicios, fol. 15).

${ }^{36}$ El Imparcial, 7 y 10 de julio de $1895,2$.

${ }^{37}$ El Imparcial, 11 de julio de 1895, 3 y, de la misma fecha, La Época, 2; El Siglo Futuro (en adelante SF), 1; La Iberia, 2; El País, 12 de julio de 1895, 1 y, del mismo día, La Correspondencia de España (en adelante CE), 3; La Dinastía, Barcelona, 3 y El Baluarte, Gerona, 5; Diario de Tenerife, 13 de julio de 1895, 1.

${ }^{38}$ Celestino Rey Joly, "La Orden de San Fernando", Revista de la Real Academia Hispano-Americana de Ciencias y Artes de Cádiz, no. extraordinario (1916): LXXIV.
} 
de su honor profesional, de su espíritu generoso y de su españolismo, han perecido en la manigua. La patria grabará esos dos gloriosos nombres en el escudo de su integridad" ${ }^{39}$.

Algunos de sus admiradores, como el periodista Ortiz de Pinedo que le había tratado en el Hospital militar de Melilla, se negaban a creer, más o menos retóricamente, en su desaparición. "Estaba entonces lleno de vida: ni vocinglero ni ostentoso; con esa tranquilidad natural, casi mecánica, del hombre que cumple imperturbable con su deber y a quien la reflexión se impone en todos los trances de la vida". Después de aquello, añadía, nada se había sabido, "pero los héroes no permanecen largo tiempo en la obscuridad" 40 . Estaba en lo cierto, poco después el Diario de Zaragoza desmintió su desaparición mediante testimonios familiares ${ }^{41}$. El propio interesado lo haría, algo más tarde, en carta a La Independencia Médica de Barcelona, que fue ampliamente difundida ${ }^{42}$.

A finales de agosto de 1895 se le ascendió a médico mayor ${ }^{43}$, pero eran muchas las voces que pedían para él la Laureada. Su amigo y compañero del cuerpo de Sanidad Militar, Francisco Triviño Valdivia ${ }^{44}$, publicó entonces bajo el seudónimo Diviaval, acrónimo evidente de su segundo apellido, una nota de protesta, en la que solicitó que se le otorgara de una vez la recompensa ${ }^{45}$. Ésta llegó, a principios de diciembre, tras la preceptiva celebración del juicio contradictorio, de segunda clase y con pensión anual de 1500 pesetas $^{46}$. Finalmente se publicó la real orden, datada el 26 de diciembre de $1895^{47}$.

El relato de los hechos, tanto en la prensa oficial como en la comercial y profesional $^{48}$, es fantasioso. Resulta imposible que apenas cuatro decenas de hombres,

39 “Crónicas breves”, El Imparcial, 12 de julio de 1895, 1. Se hicieron eco de este elogio otros medios, como por ejemplo La Rioja, Logroño, 13 de julio de 1895, 1.

${ }^{40}$ F. O. de P., "Un héroe. Don Urbano Orad", El Liberal, 14 de julio de 1895, 1. El artículo fue reproducido en Heraldo de Baleares, Palma de Mallorca, 16 de julio de 1895, 1.

${ }^{41}$ La noticia, del 23 de julio, fue recogida por La Dinastía, 24 de julio de 1895, 2.

${ }^{42}$ La Regeneración Médica (en adelante RM), 14, Salamanca, 31 de octubre de 1895, 123-124; El Guadalete, Jerez de la Frontera, 26 de noviembre de 1895, 1.

${ }^{43}$ El Liberal, 31 de agosto de 1895, 2 y, con la misma fecha, SF, 4; CM, 1; El Imparcial, 1, etc. No obstante, en los anuarios militares de 1895 y 1896, figuró como médico primero y médico mayor "graduado", lo mismo que en años anteriores. En los de 1897 y 1898 consta ya como médico mayor efectivo pero, en el de 1899 , pasó a figurar como comandante del cuerpo de Inválidos. Había ingresado provisionalmente en este cuerpo (La Época, 4 de septiembre de 1898, 3), al ser declarado inválido en su empleo (28 de agosto de 1898), y de modo definitivo el 11 de abril de 1900, al certificarse la irreversibilidad de su invalidez. Consta también, en su hoja de servicios (fols. 1, 15 y 16), su designación efectiva como médico mayor por mérito de guerra, con antigüedad del 27 de junio de 1895, según real orden del 7 de septiembre de este mismo año, en virtud de su heroico comportamiento.

${ }^{44}$ Siendo ya coronel médico (llegaría a Inspector), publicó en Melilla Del Marruecos español, en la imprenta de El Telegrama del Rif, con prólogo de José Ortega Munilla, en 1920.

${ }^{45}$ El Imparcial, 28 de agosto de 1895, 1.

${ }^{46}$ La Unión Católica, 4 de diciembre de 1895, 3; La Época, 5 de diciembre de 1895, 2.

${ }^{47}$ CM, 28 de diciembre de 1895, 2; La Época, 29 de diciembre de 1895, 1 y, del mismo día, El Liberal, 1; La Dinastía, Barcelona, 2 de enero de 1896, 2, y su consabida hoja de servicios, fol. 16.

${ }^{48}$ RM, 33, 15 de agosto de 1896, 244-245. Se llegó a hablar de "1000 rebeldes" contra la pequeña fuerza, como se lee en P. Giralt, Historia contemporánea de la isla de Cuba (La Habana: Imp. del "Avisador Comercial", 1896), 82-83. También es hiperbólica la inane entrevista que le hizo Luis Morote, en el hotel 
algunos de ellos heridos, se enfrentasen a varios cientos de aguerridos mambises y salieran airosos, por mucho empeño y valor que le pusieran al asunto. Existe una explicación plausible. La dio el propio Orad muchos años más tarde. A las ocho de la noche, ya oscurecido, se le ocurrió la idea de ordenar a un corneta que tocara alto el fuego y, de inmediato, llamada de batallón. "Fue una ocurrencia providencial. Los insurrectos creyeron que venían en nuestro auxilio fuerzas considerables, y se retiraron. Nos dejaron tranquilos, y después de hacer una nueva cura a los heridos me curé yo"49. No hay duda que la acción constituyó una clara muestra de "heroico arrojo, serenidad y buen espíritu militar", tal como señalaba la propia real orden, y, desde luego, también de habilidad, capacidad de improvisación e inteligencia.

La noticia repercutió incluso en el exterior ${ }^{50}$, e hizo que se promovieran suscripciones entre médicos y periodistas para costearle las insignias en fraternal homenaje $\mathrm{e}^{51}$. A principios de agosto fueron entregadas en el negociado de Sanidad Militar, al objeto de que le fueran impuestas con el protocolo de rigor ${ }^{52}$, cuando regresara de Cuba. También el Colegio de Médicos de Zaragoza le nombró socio de mérito y acordó ofrecerle una placa con los nombres de los colegiados ${ }^{53}$. La prensa ilustrada publicó litografías del famoso combate ${ }^{54}$ y elegantes retratos del héroe. "La ciencia y el valor unidos han hecho del Sr. Orad un sacerdote y un héroe. Un sacerdote en el sagrado ejercicio de su profesión; un héroe luchando contra los enemigos de la patria" ${ }^{\text {. }}$.

El 19 de agosto de 1897, en horas de la noche, llegó a la estación de Zaragoza procedente de Santander, tras retornar de Cuba, de donde había salido el 30 de julio anterior. La Cruz Roja, Sanidad Militar, Colegio de Médicos, prensa y numerosos amigos le esperaban para felicitarle. A partir de entonces se prodigaron como era costumbre los banquetes de homenaje y los brindis, que el biografiado supo capear con cortesía y notable sencillez. Se le otorgó, además, la vicepresidencia segunda de la Cruz Roja de Zaragoza ${ }^{56}$.

\footnotetext{
Inglaterra de La Habana, el 22 de diciembre de 1896, aunque se publicó, a cuatro columnas, en El Liberal, 9 de enero de 1897, 1. Otras fuentes de antaño y hogaño apuntan la cifra de "unos 800 mambises" (Belaústegui Fernández, José Salvany y otros médicos, 89). Las referencias documentales, como por ejemplo las contenidas en su expediente militar, tampoco ofrecen una descripción exacta del acontecimiento.

${ }^{49}$ C. Jaquotot, "Los caballeros de San Fernando", 12 de febrero de 1930, 14.

50 "Naval and Military Medical Services", The British Medical Journal, March 7, 1896, 632.

${ }^{51}$ El Guadalete, 27 de febrero de 1896, 1; RM, 29 de febrero de 1896, 62; La Iberia, 1 de marzo de 1896, 3; CM, 3 de marzo de 1896, 3; RSM, 210, 15 de marzo de 1896, 137-138.

${ }^{52}$ CE, 9 de agosto de 1896, 3; La Época, 10 de agosto de 1896, 3, y, de la misma fecha, El Imparcial, 2 y Diario Oficial de Avisos de Madrid, 2.

${ }^{53} \mathrm{CM}, 30$ de abril de $1896,2$.

${ }^{54}$ La Ilustración Ibérica, Barcelona, 27 de julio de 1895, 468.

${ }^{55}$ La Ilustración Nacional, 24, 28 de agosto de 1896, 371 y 381.

${ }^{56}$ El Imparcial, 20 de agosto de 1897, 3 y CM, 2; El Liberal, 22 de agosto de 1897, 2 y El Día, 2; El País, 23 de agosto de 1897, 2 y La Izquierda Dinástica, 25 de febrero de 1898, 1.
} 
Orad, junto a su familia, retornó al Norte de África. En Melilla estaba enterrada una de sus hijas ${ }^{57} \mathrm{y}$, a pesar de los pesares, la plaza les había enamorado a todos. Consta, por ejemplo, que los nueve miembros de su casa desembarcaron en Ceuta, provenientes de Málaga, a principios de junio de $1900^{58}$, seguramente un alto en el camino.

En febrero de 1903 tuvo la alegría de que le naciera otro hijo ${ }^{59}$. Pero no le faltaron sinsabores, como los que le produjo su etapa en la gerencia del Economato militar, que desempeñó con rigor, pero que generó una pequeña polémica en la prensa ${ }^{60}$.

En febrero de 1905 asistió a Sidi Taieb, hijo del jeque, místico y rebelde BouAmama (o Bou Hamama), quien había acudido enfermo a Melilla, al objeto de tratarse unas "pertinaces calenturas"61.

El 17 de diciembre de ese mismo año, se publicó su ascenso a teniente coronel del cuerpo de Inválidos ${ }^{62}$. Pero, sin duda, el hecho más destacado de Orad en esta época fue su activa participación en el Segundo Congreso Africanista.

\section{El Segundo Congreso Africanista (Zaragoza, 1908)}

Orad presentó una comunicación en el Segundo Congreso Africanista, que se celebró en el Círculo Mercantil, Industrial y Agrícola de la capital aragonesa, entre el 26 y el 31 de octubre de 1908 por iniciativa de los Centros Comerciales Hispano-Marroquíes. Las actas se publicaron hacia junio de 1909, aunque el catálogo colectivo del Patrimonio Bibliográfico Español y, de hecho, todas las bibliotecas importantes donde se custodia el libro lo datan en el propio año 1908, de acuerdo con la portada interior de la obra, pero es un error. Salió en la imprenta de "España en África", en Barcelona, a finales de la primavera del año siguiente. Orad acudió, pues, como delegado de la Sociedad Industrial del Norte de África para plantear cuestiones relacionadas con las comunicaciones, la enseñanza del árabe, la emigración, la necesidad de armonizar los poderes civil y militar y los impuestos ${ }^{63}$, sobre todo en relación con Melilla, la odalisca de sus amores, pero también tuvo varias intervenciones críticas que, al menos en parte, fueron recogidas y publicadas.

Inauguró las sesiones Rafael María de Labra, toda una institución en los temas más conspicuos del colonialismo español ${ }^{64}$. Su largo parlamento no es fácil de resumir en pocas

\footnotetext{
${ }^{57}$ El Liberal, 9 de enero de 1897, 1.

${ }^{58}$ La Correspondencia Militar (en adelante CMi), 9 de junio de 1900, 3.

${ }^{59}$ El Telegrama del Rif (en adelante TR), Melilla, 22 de febrero de 1903, 2.

${ }^{60}$ TR, 16 y 20 de septiembre de 1903, 2 y 1.

${ }^{61}$ El Globo, 9 de febrero de 1905, 3: "El enfermo es asistido por el reputado médico D. Urbano Orad".

${ }^{62}$ DOMG, 280, 17 de diciembre de 1905, Tomo IV, 680, con efectividad del 23 de noviembre anterior. La real orden está datada a 15 de diciembre.

${ }^{63}$ Segundo Congreso Africanista: celebrado en Zaragoza, 1908 (Barcelona: Imp. España en África, 1908) [1909], 72.

${ }^{64}$ María Dolores Domingo Acebrón, Rafael María de Labra: Cuba, Puerto Rico, las Filipinas, Europa y Marruecos en la España del Sexenio Democrático y la Restauración (1871-1918) (Madrid: CSIC, 2006).
} 
palabras, pero estuvo centrado en los siguientes puntos que él mismo se encargó de esbozar:

1. España no podía sustraerse a la influencia de los problemas mediterráneos, sobre todo después del tratado anglo-francés de 1904, de la visita del káiser a Tánger y del Acta de Algeciras.

2. La expansión de España por el Norte de África era una aspiración "perfectamente abonada" por la historia, por la "economía social" de Marruecos, por la inmediatez de los mercados, por la tendencia de todos los "pueblos cultos de nuestro tiempo" de dar salida a sus productos y por la relevancia de la emigración.

3. Pero, además, por otra razón fundamental a juicio de Labra, la necesidad de España de no quedar aislada o circuida por el Sur, mediante el establecimiento en el antiguo imperio cherifiano de una gran colonia por Francia, potencia cuya experiencia e intereses en el Magreb resultaban evidentes. Sobre todo porque, al mismo tiempo, "la línea del Pirineo nos separaba del mundo europeo y el peso de Inglaterra en Portugal contribuiría a hacer más difícil nuestra libertad de acción, ya vigilada desde el Peñón de Gibraltar" ${ }^{\circ 5}$.

Orad, por su lado, tuvo la oportunidad de intervenir en asuntos de importancia a lo largo de las sesiones del congreso, como fueron los relacionados con los temas que le habían sido encomendados y que desarrolló en su ponencia, como luego se verá. Solicitó el establecimiento de una línea marítima semanal entre Melilla y Almería, que debería combinarse con el exprés Almería-Madrid. También propuso una escala en Tetuán para las comunicaciones con las plazas del Norte de África. Reforzó, asimismo, las observaciones de Emilio Bonelli sobre la difusión del árabe, y sugirió textualmente que, para potenciar su aprendizaje, debía declararse mérito preferente la posesión de este idioma, en igualdad de condiciones con otros candidatos, para obtener toda clase de cargos en las posesiones africanas ${ }^{66}$.

Ya en terreno propio sobresalió en el punto octavo, relativo al sistema administrativo civil y militar. Estuvo de acuerdo con la idea de la comisión respectiva del congreso, que se había decantado por normalizar el régimen civil, administrativo y militar de las plazas del Norte de África, mediante la supresión de varios artículos del Código de Justicia Militar, aunque se mantuvieran, en su caso, algunas leyes especiales, de acuerdo con la misión peculiar de España en la zona. Así, tal como se recoge en las actas, "el Sr. Orad aplaude la referida conclusión, censura los derechos abusivos de que gozan los militares en nuestras plazas del Norte de África y lamenta que los paisanos carezcan de todo derecho, como también de los organismos que hoy reclama la vida del comercio y de

\footnotetext{
${ }^{65}$ Segundo Congreso Africanista, 44-45.

${ }^{66}$ Segundo Congreso Africanista, 126, 139-140.
} 
la industria". Orad aprovechó, de nuevo, para reclamar derechos administrativos y civiles en favor de Melilla, que en aquellas fechas carecía aún de ayuntamiento propio ${ }^{67}$.

Los miembros de la comisión también se mostraron unánimes en la necesidad de contar con un cuerpo de ejército colonial que, según matizó Orad, podría basarse en la compañía de moros del Rif, pero con mejores condiciones salariales, ya que por entonces, al retirarse, no superaban los 76 céntimos diarios tras veinticinco años de servicio. Se hacía necesario, por tanto, asimilarlos al modelo establecido por Francia para los tiradores argelinos. Para ello, se podrían arbitrar recursos mediante la reducción al mínimo de las compañías de mar de Ceuta y Melilla, "que no llenan ningún cometido militar ni marinero", así como mediante la disolución del escuadrón de caballería de Ceuta, "otro cuerpo perfectamente inútil", o del propio grupo Disciplinario. Todo ello porque la "índole del servicio en África" exigía la creación de un cuerpo de ejército colonial ${ }^{68}$.

El texto de su propia intervención ocupaba catorce páginas ${ }^{69}$. Ponderaba, en primer lugar, la armonización de los poderes civil y militar que, en su opinión, podrían operar al mismo tiempo de manera equilibrada, tal como sucedía en diversos enclaves fronterizos del resto del mundo, sin menoscabo de ninguno de ellos. Veracruz, Callao u Orán habían tenido ayuntamientos y jueces civiles, sin que fuera obstáculo para que funcionaran normalmente los fuertes, las baterías, los arsenales y los regimientos. Esto demuestra perfectamente que pueden existir en las plazas fuertes y fronterizas ayuntamientos, tribunales ordinarios, policía civil, etc., sin detrimento de la autoridad militar, la que conserva aquellas facultades extraordinarias que afectan al orden público o a la defensa, insistió.

En este contexto, Orad se reveló como un decidido partidario de la separación de ambos poderes, no solamente para favorecer la expansión comercial sino también por conveniencia pública y, según afirmó, "por respeto a los derechos" de los tres millares de españoles que residían en las plazas de África. Y, asimismo, "por dignidad del Estado español, que tiene convertidas a Ceuta y Melilla", en particular a ésta última, "en ciudades colonia". Aprovechó entonces para vindicar, a favor de Melilla, no solamente su constitución como municipio, sino una seria de reformas estructurales de interés, como por ejemplo el saneamiento urbano, la canalización del servicio de agua, el establecimiento de edificios para escuelas y otras infraestructuras. Criticó, asimismo, la dilapidación de recursos mediante la construcción de pabellones para oficiales y otros gastos superfluos como los relativos al sostenimiento de un colegio de enseñanza y una escuela de artes y oficios, "perfectamente inútiles, pero que justifican el que dos docenas de militares cobren gratificaciones como profesores". Las escuelas públicas, subrayaba también, "no se proveen en forma legal, porque se dan caprichosamente a parientes de militares".

\footnotetext{
${ }^{67}$ Segundo Congreso Africanista, 161-163.

${ }^{68}$ Segundo Congreso Africanista, 165-166.

${ }^{69}$ Segundo Congreso Africanista, XXXIV-XLVIII.
} 
También defendió, con argumentos propios, la tesis de la creación de un cuerpo de ejército colonial, tal como había sostenido en los debates del congreso. Un regimiento de rifeños que "desempeñaría en paz o en guerra servicios que difícilmente podrían cumplir cuerpos regulares europeos". Insistió, con pasión, en la necesidad de contar con personal militar más escogido que el de las guarniciones peninsulares, así como también con un núcleo fijo de veteranos para situaciones especiales. Planteó, igualmente, la conveniencia de estimular, mediante premios, a los reemplazos para que prestaran el servicio en África, que era superior en dos años al de la Península. Entre otras ventajas, afirmó, se evitaría con ello que únicamente las provincias de Andalucía y Levante proveyeran la mayor parte de los reclutas para las guarniciones africanas. Puso como ejemplo "el caso ocurrido cuando los sucesos de 1893 que, de 56 soldados que murieron, 43 eran de Andalucía”.

Rechazó, además, la existencia en Melilla del citado grupo Disciplinario que guarnecía la plaza, ya que estaba formado por individuos procedentes de los presidios y constituía, por tanto, "un deshonor para España tenerlo en contacto con un país que pretendemos civilizar y atraernos las simpatías de sus habitantes”. Es más, según apuntó, "sería interminable la lista de delitos cometidos por esa gente maleante, que presentamos a los indígenas vestidos con el uniforme de soldado español". Sugirió, en fin, la disolución de esta fuerza y la agregación de sus soldados a la Penitenciaría militar de Mahón.

Al objeto de reforzar, igualmente, la defensa de las plazas de soberanía y para proteger a las diez mil personas que vivían fuera de sus murallas, sugirió también la creación de una especie de milicia parecida a la de Malta, la Jeomary inglesa o los batallones territoriales del ejército de Argelia. Este cuerpo, "sin las ridiculeces de uniformes vistosos ni formaciones teatrales, concretándose a la instrucción de tiro todos los días festivos", podría sostenerse con una subvención del Ministerio de la Guerra y con las cuotas que pagarían los vecinos que se eximieran del servicio por diversos motivos.

Se mostró partidario, asimismo, de que se creara una Dirección General de África, que dependería de Presidencia del Gobierno e incluiría todas las posesiones africanas hasta Guinea. Este organismo debería estar a cargo de un hombre público de reconocido prestigio que, además, tendría que conocer perfectamente los problemas de la región. También debería hablar árabe y francés, así como poseer "profundos conocimientos de la Geografía e Historia de Marruecos", es decir, "una cosa parecida al Brevet de aptitudes exigido a los funcionarios administrativos en la Argelia y Túnez". Sugirió, igualmente, una serie de medidas para evitar el caos burocrático existente en aquellas fechas.

Finalmente, en relación con el tema de los impuestos, planteó la necesidad de favorecer con medidas fiscales el desarrollo de la industria, la propiedad y el comercio, pues, de lo contrario, una parte significativa de la población, que era de origen musulmán y hebreo, buscaría mejores mercados en Argelia. No parecía justo, además, equipararlos en impuestos a los habitantes de la Península, pues tampoco poseían los mismos derechos. 
Tras la publicación de las resoluciones del congreso, las reflexiones de Orad suscitaron el interés de diversos sectores. La prensa de Almería, por ejemplo, se sintió agradecida y llamó la atención sobre el tema de las comunicaciones, que consideraba de vital importancia ${ }^{70}$.

Sus observaciones también dieron lugar a reseñas positivas en medios jurídicos, tanto civiles como militares. La Gaceta Jurídica de Guerra y Marina reprodujo textualmente un significativo fragmento acerca de la armonización entre los poderes civil y militar, sin detrimento de las partes ${ }^{71}$. Y otro tanto puede decirse de El Foro Español que recogió un artículo, publicado inicialmente por Manuel Conrotte ${ }^{72}$ en la Revista de los Tribunales, sobre el mismo asunto ${ }^{73}$. Este impacto mediático venía justificado, además, por la coyuntura nacional e internacional respecto a Marruecos. Por todo ello, ciertas reflexiones de Orad concitaron el apoyo de grupos jurídicos y profesionales que defendían las reformas y, al mismo tiempo, diversos intereses corporativos, políticos e institucionales.

En agosto de 1909, en el marco del nuevo conflicto con las cabilas rifeñas, en el que, por cierto, falleció el citado coronel Venancio Álvarez Cabrera, general a título póstumo, grado 33 y amigo personal de Julio Cervera, Orad recibió, en tanto que presidente de la comisión de la Cruz Roja en Melilla, una generosa oferta. Su colega de La Coruña le rogó, en una carta "llena de entusiasmo patriótico", que hiciera todas las gestiones para el traslado de una ambulancia a Melilla, que dispondría no solo del instrumental necesario, sino también de un experimentado equipo médico-sanitario, todo ello financiado por los donantes $^{74}$. Se sabe que, en estas fechas, Orad estuvo en primera línea de fuego, curando heridos en la acción del Barranco del Lobo y en la toma de Taxdir ${ }^{75}$.

\section{Atardecer en Madrid}

A finales de octubre o principios de noviembre de 1910 pasó a residir en Madrid ${ }^{76}$. Posteriormente, se le autorizó a viajar por diversas ciudades peninsulares, así como también

\footnotetext{
70 "El Congreso africanista de Zaragoza”, La Independencia, Almería, 11 de junio de 1909, 1.

71 "La justicia en las plazas de África”, Gaceta Jurídica de Guerra y Marina, 25 de junio de 1909, 180-181.

${ }^{72}$ El jurista y ensayista Manuel Conrotte Méndez se había mostrado, además, decidido partidario en materia civil de la actuación de los tribunales nativos, pues, tal como indicó, "el musulmán deberá ser juzgado con arreglo a sus leyes, cuyas raíces se encuentran en sus libros religiosos". En 1909 publicó España y los países musulmanes durante el ministerio de Floridablanca, obra que sigue siendo útil.

73 "Nuestra futura administración de justicia en África", El Foro Español, 10 de octubre de 1912, 295-297.

${ }^{74} \mathrm{CMi}, 31$ de agosto de $1909,1$.

${ }^{75}$ La Libertad, 20 de febrero de 1935, 2. Se le concedió, por estos servicios, la cruz de segunda clase del mérito militar con distintivo rojo, según se especifica en su hoja (fol. 17), por su asistencia voluntaria a los heridos en el combate del 27 de julio de 1909 y en los hospitales de la plaza.

${ }^{76}$ RSM, 22, 15 de noviembre de 1910, 710.
} 
por Francia e Italia ${ }^{77}$. En 1912 se le concedieron, además, ocho meses de licencia para $\mathrm{Cuba}^{78}$. Un año después se le ascendió a coronel de Inválidos ${ }^{79}$.

En contacto siempre con sus camaradas y compañeros de la milicia, el 18 de mayo de 1915 estuvo presente en el acto de imposición de la placa y venera de San Fernando al cabo Salvador Miguel y, además, presidió el almuerzo que tuvo lugar en el famoso hotel Inglés ${ }^{80}$.

Aunque puede seguirse su huella, con anotaciones de escasa importancia, en la prensa de estos años, quizá lo más relevante fue la concesión, el 25 de noviembre de 1925 , del sueldo de general de brigada, pues reunía las condiciones reglamentarias ${ }^{81}$. El 2 de enero de 1926 participó, junto a varios de sus compañeros laureados, en el banquete que les ofreció el monarca en el Ritz y que la prensa de la época ilustró convenientemente ${ }^{82}$. El 22 de junio de 1927 le fue otorgada, a su vez, la Medalla de Sufrimientos por la Patria, sin pensión ${ }^{83}$. Sabemos, además, que concedió algunas entrevistas a los medios que se interesaron por su pasado heroico, como por ejemplo la que se publicó en La Nación ${ }^{84}$. Consta también su nombre, junto al de su hijo Urbano Orad de la Torre y al de la viuda y familia de Simarro ${ }^{85}$, entre los suscriptores de uno de los homenajes que, en 1932, se tributaron al teniente coronel de Infantería, Julio Mangada Rosenörn, personaje singular por varios conceptos ${ }^{86}$.

Falleció en Madrid el 18 de febrero de 1935, a pesar de que se ha datado su óbito dos días antes ${ }^{87}$, pues el periódico filo-masónico La Libertad publicó su esquela el día 19 y anunció la conducción del cadáver, "hoy martes 19, a las once de la mañana" ${ }^{88}$. En la edición del día siguiente, además, se informó del sepelio. El cadáver fue trasladado, a la hora convenida, al Cementerio Municipal del Este y "su entierro ha sido civil". Se llamó la atención, además, sobre el "hecho de que, a pesar de tratarse de un verdadero prestigio militar, no asistía al entierro otra representación oficial que la comisión de su cuerpo" de Sanidad Militar ${ }^{89}$.

\footnotetext{
${ }_{77}^{77} \mathrm{CMi}, 24$ de julio de $1911,3$.

${ }^{78} \mathrm{CMi}, 25$ de octubre de 1912, 1.

${ }^{79} \mathrm{CMi}, 22$ y 24 de noviembre de 1913,1 y 3.

${ }^{80} \mathrm{CMi}, 18$ de mayo de $1915,3$.

${ }^{81}$ DOMG, 265, 27 de noviembre de 1925, Tomo IV, 557.

${ }^{82}$ La Época, 2 de enero de 1926, 3; El Imparcial, 3 de enero de 1926, 1 y 4. Asistieron 36 de los 79 caballeros de San Fernando que figuraban en el Anuario Militar.

${ }^{83}$ DOMG, 137, 23 de junio de 1927, Tomo I, 938.

${ }^{84}$ El 12 de febrero de $1930,14$.

${ }^{85}$ Heraldo de Madrid, 31 de agosto de 1932, 15.

${ }^{86}$ Manuel de Paz Sánchez, Militares masones de España. Diccionario biográfico del siglo XX (Alzira [Valencia]: Centro Francisco Tomás y Valiente de la UNED, 2004), 259-260.

${ }^{87}$ Belaústegui Fernández, José Salvany y otros médicos, 86.

${ }^{88}$ La Libertad, 19 de febrero de 1935, 10.

${ }^{89}$ La Libertad, 20 de febrero de 1935, 2, ya citado. Se refirió brevemente al óbito la RSM del 15 de marzo de 1935, 88. Consta además, como anexo a su hoja de servicios, un dictamen del Consejo Director de las órdenes
} 
El Boletín Oficial del Supremo Consejo del Grado 33 se hizo eco también de su fallecimiento y dio el pésame especial a "nuestros queridos hermanos Orad de la Torre"

Ya en nuestro tiempo se han rendido algunos homenajes a su memoria, particularmente en su región de origen, en la que se estableció un premio bajo el nombre de "Caballero Laureado de San Fernando Coronel Médico D. Urbano Santos Orad Gajías". También se otorgó su nombre al Hospital General de la Defensa, ubicado en el barrio de Casablanca (Zaragoza) ${ }^{91}$.

\section{A modo de conclusión}

Otro aragonés ilustre, cuyo legado siempre está de actualidad, don Santiago Ramón y Cajal $^{92}$, también fue, como es bien sabido, médico militar, perteneció a la misma generación de su paisano Orad y, curiosamente, también se integró en la orden del gran arquitecto del universo cuando frisaba los veinticinco años ${ }^{93}$.

¿Por qué se hacían masones estos hombres sabios, heroicos y reformadores? A veces su paso por la Orden fue bastante fugaz, pero, a lo largo de su vida mantuvieron contactos con algún que otro miembro de su antigua fraternidad masónica. Por ejemplo, en el caso de Ramón y Cajal, con su colega y amigo Luis Simarro, de quien aprendió nada

de San Fernando y San Hermenegildo, favorable a la petición de su viuda de que se le traspasara la pensión de dos mil pesetas que percibía su difunto esposo. En el escrito, que está datado a 22 de mayo de 1935, se señala "el hecho cierto del fallecimiento del referido Coronel en 18 de febrero último", aunque, al final del mismo documento, se hace constar también que la pensión habría de percibirla doña Blanca Rosa de la Torre y Morales, a partir del "17 de febrero del corriente año de 1935, siguiente día del fallecimiento del causante". Pero el error es obvio.

${ }^{90}$ Boletín Oficial y Revista Masónica del Supremo Consejo del Grado 33 para España y sus Dependencias, 411-412, marzo-junio de 1935, 12. Tanto Urbano Orad de la Torre, militar de renombre durante la Guerra Civil, como su hermano José, cuando menos, fueron también masones. El ingeniero civil José, junto a un hijo suyo, murieron al principio de la contienda, en la propia capital de España (De Paz Sánchez, Militares masones, 316-319). El periódico $A B C$ (Sevilla, 24 de abril de 1998, 57) confundió a Urbano Orad padre con Urbano Orad de la Torre, que fue homenajeado, póstumamente, por la diputación en las instalaciones del Cortijo de Cuarto, en Bellavista.

${ }^{91}$ Según se ha señalado, el centro hospitalario recibió oficialmente este nombre en 2002 (L. A. Arcarazo García y M. P. Lorén Trasobares, "La asistencia sanitaria militar en Zaragoza desde el siglo XVIII: los hospitales militares", Sanidad Militar 64, no. 3 (2008): 134-153), aunque también consta la celebración del "quincuagésimo aniversario del Hospital General de la Defensa Orad y Gajías" en el Boletín Informativo de Sanidad Militar 1 (2009): 16.

92 Alfredo Baratas Díaz, "Recientes ediciones en lengua inglesa de obras de Santiago Ramón y Cajal", Asclepio 47, no. 1 (1995): 283-286. Leoncio López-Ocón Cabrera, "La voluntad pedagógica de Cajal, presidente de la JAE", Asclepio, 59, 2 (2007): 11-36.

${ }^{93}$ Ferrer Benimeli, La masonería en Aragón (Zaragoza: Librería General, 1979), Tomo I, 139 y Tomo III, 217. Ferrer Benimeli, "El Dr. Simarro y la masonería”, Investigaciones Psicológicas 4 (1987): 211-344, especialmente 223-227. 
menos que el método Golgi ${ }^{94}$. Quizás, también, porque la amistad y la camaradería fraguaban relaciones personales, culturales y de ocio que iban más allá de los centros sanitarios y de los laboratorios.

Pero, en cualquier caso, sucede lo mismo que había acaecido con otras destacadas figuras de la medicina y de la masonería en el Norte de África y en Cuba durante esta época, como Celestino García Fernández ${ }^{95}$. Y, al igual que otras personalidades del cuerpo de Sanidad Militar en estos espacios de intensa actividad bélica durante la Restauración y la Dictadura, como fueron -aparte, claro está, de don Santiago Ramón y Cajal-, Rosendo Castells Ballespí, caballero también de San Fernando ${ }^{96}$, o Máximo Martínez Zaldívar ${ }^{97}$, por citar solamente unos pocos ejemplos significativos, Orad contribuyó también, mediante su actuación y su crítica, a la modernización del país. Nadie les pudo cuestionar su lealtad o su patriotismo, así como tampoco su fidelidad a los principios democráticos y reformistas, dos realidades que, para estos héroes de bata blanca, nunca fueron incompatibles.

\section{Bibliografía}

Allendesalazar, José Manuel. La diplomacia española y Marruecos, 1907-1909. Madrid: Ministerio de Asuntos Exteriores, 1990.

Álvarez Rey, Leandro y Fernando Martínez López. Los masones andaluces de la República, la guerra y el exilio: Diccionario biográfico. Sevilla: Universidad de Sevilla, 2014, 2 tomos.

Arcarazo García, L. A. y M. P. Lorén Trasobares. "La asistencia sanitaria militar en Zaragoza desde el siglo XVIII: los hospitales militares”. Sanidad militar 64, no. 3 (2008): 134-153.

Baratas Díaz, Alfredo. "Recientes ediciones en lengua inglesa de obras de Santiago Ramón y Cajal”. Asclepio 47, no. 1 (1995): 283-286.

\footnotetext{
${ }^{94}$ Assumpciò Vidal Parellada, Luis Simarro y su tiempo (Madrid: CSIC, 2007), 82-84. Alfredo Baratas Díaz, "Neurociencias en la Junta para Ampliación de Estudios", Asclepio 59, no. 2 (2007): 115-136. Miguel Ángel Puig-Samper, "El Dr. Simarro y el movimiento antropológico de su tiempo", Investigaciones Psicológicas 4 (1987): 115-126.

${ }^{95}$ José Luis Gómez Barceló, "Un médico en la frontera de dos mundos: Celestino García Fernández (18511908)", en Regenerar España y Marruecos: ciencia y educación en las relaciones hispano-marroquies a finales del siglo XIX, eds. Francisco J. Martínez Antonio e Irene González González (Madrid: CSIC, 2011), 385-403.

${ }^{96}$ De Paz Sánchez, Militares masones, 107-110.

${ }^{97}$ Leandro Álvarez Rey y Fernando Martínez López, Los masones andaluces de la República, la guerra y el exilio: Diccionario biográfico (Sevilla: Universidad de Sevilla, 2014), Tomo II, 690. Francisco J. Martínez Antonio, "Entre la diplomacia médica y la política sanitaria: médicos militares en el Protectorado español en Marruecos (1906-1927)", Revista de Historia Militar, Extra 2 (2012): 203-241.
} 
Baratas Díaz, Alfredo. "Neurociencias en la Junta para Ampliación de Estudios". Asclepio 59, 2 (2007): 115-136.

Belaústegui Fernández, Alejandro. José Salvany y otros médicos militares ejemplares. Inicio de una lucha contra el olvido. Madrid: Ministerio de Defensa, 2006.

Conrotte Méndez, Manuel. España y los países musulmanes durante el ministerio de Floridablanca. Madrid: Real Sociedad Geográfica, 1909.

Conrotte Méndez, Manuel. "Nuestra futura administración de justicia en África". El Foro Español, 10 de octubre de 1912.

Domingo Acebrón, María Dolores. Rafael María de Labra: Cuba, Puerto Rico, las Filipinas, Europa y Marruecos en la España del Sexenio Democrático y la Restauración (1871-1918). Madrid: CSIC, 2006.

Ferrer Benimeli, José Antonio. La masonería en Aragón. Zaragoza: Librería General, 1979, 3 tomos.

Ferrer Benimeli, José Antonio. "El Dr. Simarro y la masonería”. Investigaciones Psicológicas 4 (1987): 211-344.

Giralt, P. Historia contemporánea de la isla de Cuba. La Habana: Imp. del Avisador Comercial, 1896.

Gómez Barceló, José Luis. "Un médico en la frontera de dos mundos: Celestino García Fernández (1851-1908)". En Regenerar España y Marruecos: ciencia y educación en las relaciones hispano-marroquies a finales del siglo XIX. Editado por Francisco J. Martínez Antonio e Irene González González. Madrid: CSIC, 2011.

Jaquotot, C. "Los caballeros de San Fernando. ¿En qué hecho, cómo y cuándo ganó usted la laureada? Don Urbano Orad, coronel de Inválidos". La Nación, 12 de febrero de 1930.

López-Ocón Cabrera, Leoncio. "La voluntad pedagógica de Cajal, presidente de la JAE". Asclepio 59, no. 2 (2007): 11-36.

Martín Corrales, Eloy. Marruecos y el colonialismo español (1859-1912): de la guerra de África a la "penetración pacífica”. Barcelona: Bellaterra, 2002.

Martínez Antonio, Francisco Javier. "Entre la diplomacia médica y la política sanitaria: médicos militares en el Protectorado español en Marruecos (1906-1927)". Revista de Historia Militar Extra 2 (2012): 203-241.

Martínez Antonio, Francisco Javier e Irene González González eds. Regenerar España y Marruecos: ciencia y educación en las relaciones hispanomarroquies a finales del siglo XIX. Madrid: CSIC, 2011.

Moga Romero, Vicente. "Aproximación a la masonería de Ceuta en el siglo XIX". En La masonería en la España del siglo XIX. Coordinado por José Antonio Ferrer Benimeli. Salamanca: CEHME y Junta de Castilla y León, 1987.

Moga Romero, Vicente. Al "Oriente” de África: Masonería, Guerra Civil y represión en Melilla (1894-1936). Melilla: UNED, 2005, 2 tomos. 
Moga Romero, Vicente. La cuestión marroquí en la escritura africanista: una aproximación a la contribución bibliográfica y editorial española al conocimiento del Norte de Marruecos (1859-2006). Barcelona: Bellaterra, 2008.

Moga Romero, Vicente y Adoración Perpén Ruedan. “Orígenes ideológicos de los talleres masónicos contemporáneos en Melilla: militares y masonería (1893-1927)". En Masonería, revolución y reacción. Coordinado por José Antonio Ferrer Benimeli. Alicante: CEHME, Diputación Provincial de Alicante- Instituto Alicantino de Cultura Juan Gil-Albert, 1990.

Morales Lezcano, Víctor. España y el Norte de África: el Protectorado en Marruecos (1912-1956). Madrid: UNED, 1986.

Morales Lezcano, Víctor. El colonialismo hispano-francés en Marruecos (1898-1927). Granada: Universidad de Granada, 2002.

Pastor Garrigues, Francisco M. A las puertas del Protectorado: las negociaciones secretas hispano-francesas en torno a Marruecos (1901-1904). Sevilla: Universidad de Sevilla, 2013.

Paz Sánchez, Manuel de. Militares masones de España. Diccionario biográfico del siglo $X X$. Alzira (Valencia): Centro Francisco Tomás y Valiente de la UNED, 2004.

Paz Sánchez, Manuel de. La masonería y la pérdida de las colonias. Estudios. Santa Cruz de Tenerife: Ediciones Idea, 2006.

Paz Sánchez, Manuel de. "España, Cuba y Marruecos: masonería, identidades y construcción nacional”. Anuario de Estudios Atlánticos 55 (2009): 273-310.

Pina, Jorge. "Julio Cervera Baviera. Apuntes biográficos". En Conmemoración de la expedición cientifica de Cervera-Quiroga-Rizzo al Sáhara Occidental en 1886. Editado por José A. Rodríguez Esteban. Madrid: CSIC, 2008.

Puig-Samper, Miguel Ángel. "El Dr. Simarro y el movimiento antropológico de su tiempo". Investigaciones Psicológicas 4 (1987): 115-126.

Ramiro de la Mata, Javier. Origen y dinámica del colonialismo español en Marruecos. Ceuta: Archivo Central, 2002.

Rey Joly, Celestino. "La Orden de San Fernando". Revista de la Real Academia HispanoAmericana de Ciencias y Artes de Cádiz, no. extraordinario (1916): LXX-LXXIV.

Salafranca Ortega, Jesús F. El sistema colonial español en África. Málaga: Algazara, 2001.

Sampedro Ramo, Vicent. Julio Cervera Baviera, republicano y masón. Castellón de la Plana: Universitat Jaume I, 2015.

Sánchez Montoya, Francisco. "Los libros falsos de Tánger y apuntes sobre la represión de la masonería en Ceuta”. En La masonería en Madrid y en España del siglo XVIII al XXI. Coordinado por José Antonio Ferrer Benimeli. Zaragoza: CEHME, 2004.

Serna, Alfonso de la. Al sur de Tarifa: España-Marruecos: un malentendido histórico. Madrid: Marcial Pons, 2002. 
Soldevilla, Fernando. Año político. 1895. Madrid: Imp. de Enrique Fernández de Rojas, 1896.

Triviño Valdivia, Francisco. Del Marruecos español. Prólogo de José Ortega Munilla. Melilla: Imp. de El Telegrama del Rif, 1920.

Vicente Hernández, Juan. La prensa en el Archivo General Militar de Segovia: catálogo (1810-1935). Madrid: Fundación Mapfre Tavera, 2004.

Vidal Parellada, Assumpciò. Luis Simarro y su tiempo. Madrid: CSIC, 2007.

Youssef, Akmir. De Algeciras a Tetuán, 1875-1906: orígenes del proyecto colonialista español en Marruecos. Rabat: Instituto de Estudios Hispano-Lusos, 2009. 